\title{
Analysis of Micro strip patch Antenna Using Coaxial feed and Micro strip line feed for Wireless Application
}

\author{
Ms.Varsharani Mokal ${ }^{1}$, Prof S.R.Gagare ${ }^{2}$, Dr.R.P.Labade ${ }^{3}$ \\ ${ }^{1,2,3}$ (Department OF Electronics and Telecommunication, Amrutvahini COE/SSPU,India)
}

\begin{abstract}
This work describes the performance analysis of micro strip rectangular patch antenna using coaxial feeding technique and micro strip line feeding technique for wireless application i.e. for Bluetooth application. In this work two types of feeding techniques (Micro strip line feed, coaxial probe feed) are used. The Proposed antenna is designed using FR-4 dielectric substrate which has a dielectric constant of 4.4 and loss tangent of 0.02 with dimensions of $46.70 \times 38.60 \times 1.6 \mathrm{~mm}^{3}$. The proposed antenna calculations are done for the frequency $2.4 \mathrm{GHz}$. The Return loss ,Impedance, VSWR, Efficiency ,Gain and Radiation pattern are simulated \& comparison of all these parameters for strip line and coaxial feeding is studied. Simulation is done by using CADFEKO Suite 7.0.
\end{abstract}

Keywords - Bluetooth, Coaxial Feed, Feeding technique, Microstrip Antenna, Microstrip feed line.

\section{INTRODUCTION}

The trend of wireless communication systems has increased tremendously. As a vital part of these systems, antenna is one of the most important design issues in modern mobile communication systems. So an antenna can be defined as a metallic device for radiating or receiving the EM waves. Antenna has functions like transducer which converts electrical energy into EM energy at transmitter side \& it converts EM energy to electrical energy at receiver side. Now a days in Mobile communication, there is an increased demand for compact and low profile antennas. So the micro strip antennas are best choice because of its attractive features such as compact structure, light weight, easy fabrications, simple geometry and compatibility with monolithic microwave integrated circuits.[1]-[2].

Micro strip patch antennas are fed in four different techniques 1) Contacting and 2) Non-contacting. In contacting method RF power is fed directly to the radiating patch using a connected element, they are micro strip feed and coaxial feed [1-3]. In non-contacting method electromagnetic coupling is done to transfer the power between the feed line and radiating patch they are aperture coupled feed and proximity coupled feed [5]. In this micorstrip line feed technique, a conducting strip is connected directly to the edge of the microstrip patch.In coaxial feeding technique the inner conductor of the coaxial connector extends through the dielectric and is soldered to the radiating patch, while the outer conductor is connected to the ground plane. Main advantage of coaxial feeding techniques is that the feed can be placed at any desired position inside the patch in order to obtain impedance matching Mirostrip antennas have important applications especially in the field of medical, military, mobile and satellite communications.[6]

In this work, the Proposed antenna is designed using FR-4 dielectric substrate which has a dielectric constant of 4.4 and loss tangent of 0.02 with dimensions of $46.70 \times 38.60 \times 1.6 \mathrm{~mm}^{3}$. The proposed antenna calculations are done for the frequency $2.4 \mathrm{GHz}$.Simulation is done by using cadfeko suite7.0. The Return loss, impedance,VSWR,efficiency,gain and Radiation pattern are simulated \& comparison of all these parameters for strip line and coaxial feeding is studied. So In this work a comparative analysis has been done considering coaxial and microstrip line feeding techniques [8]-[9].

\section{MICROSTRIP ANTENNA AND FEEDING TECHNIQUES}

The geometry of micro strip patch antenna is shown in fig.1.It consist of four parts ; radiating element patch, dielectric substrate, ground plane and feed line[5]. Patch is a radiating element and it can be available in different shapes like square,rectangular,circular,triangular etc. Feed line distributes RF power to different Part of antenna. A patch radiates from fringing fields around its edges. The length $\mathrm{L}$ of radiating patch in this antenna is usually $0.333 \lambda_{0}<\mathrm{L}<0.5 \lambda_{0}$, the thickness $\mathrm{t}$ of patch is very much less than $\lambda_{0}$, where as height $\mathrm{h}$ of dielectric substrate is ranges from $0.003 \lambda_{0}$ to $0.05 \lambda_{0}$, where $\lambda_{0}$ is the free space wavelength. The dielectric constant $\varepsilon_{\mathrm{r}}$ of the dielectric substrate is $2.2 \leq \varepsilon_{\mathrm{r}} \leq 12$ [1].In this work we have design rectangular shape Micro strip antenna first using coaxial feed technique for feeding the patch of antenna. Then we design same antenna using microstrip line feeding techniques. 


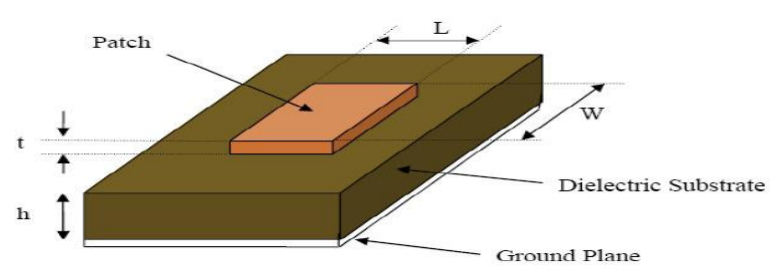

Fig.1. Geometry of microstrip Antenna[5]

In this work we have designed antenna using coaxial feed and microstrip line feed.Microstrip patch antennas can be fed by a variety of methods. These methods are classified into two types- contacting and noncontacting. In the contacting method, the RF power is fed directly to the radiating patch using a connecting feed. In the non-contacting scheme, electromagnetic field coupling is done to transfer power between the microstrip line and the radiating patch. In this technique a con- ducting strip directly connected to the patch which is smaller in dimension as compare to patch. It is very easy to fabricate, very simple in modeling and match with characteristic impedance $50 \Omega$ or $75 \Omega$. This can achieve by properly controlling the inset position [1-2]. Microstrip Line Feed shown in below fig.2. The structure of coaxial feed is shown in fig.3.In this technique the outer conductor of the coaxial cable is connected to the ground plane, and the center conductor is extended up to the patch antenna [6]. Feed can be placed any where inside the patch to match with its input impedance.

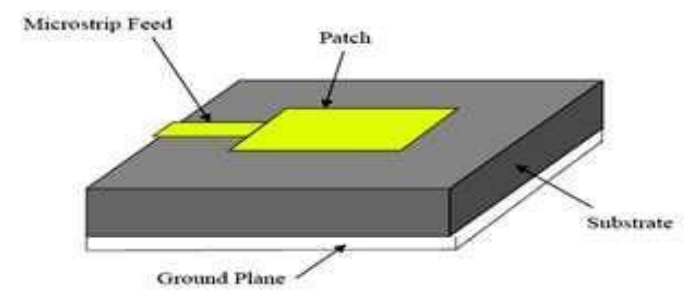

Fig.2. Geometry of microstrip line feed Antenna[6]

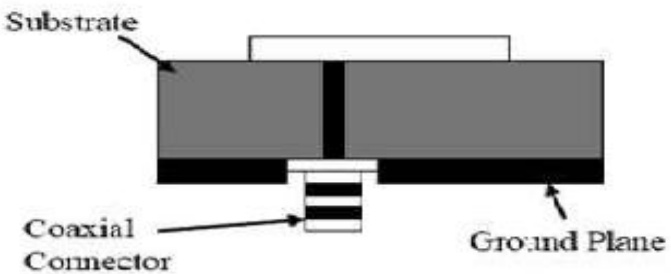

Coasicl Or Probe Feeding

Fig.3. Geometry of Coaxial feed Antenna[6]

\section{ANTENNA DESIGN}

The geometry of the designed coaxial feed micro strip patch antenna is as shown in figure.4. The antenna is designed using FR-4 dielectric of thickness $1.6 \mathrm{~mm}$ with dimensions of $46.70 \mathrm{x} 38.60 \times 1.6 \mathrm{~mm}^{3}$ and feed by a Co- axial feed of $50 \Omega$. The relative permittivity and loss tangent of the substrate is 4.4 and 0.02 respectively[3]-[4] Equations (1-8) are used for the proposal of rectangular micro strip patch antenna. Feed points location inside the patch are $\mathrm{X}=4.12 \mathrm{~mm}$ and $\mathrm{Y}=7.17 \mathrm{~mm}$ from the centre. The antenna is designed by using following "equation 1 to 8 ".

The Width of the Patch (Wp): The width of the microstrip patch antenna is given in "equation 1".

Width of patch(Wp):

$$
W P=\frac{c}{2 \& f r \sqrt{\frac{E r+1}{2}}}
$$

Effective dielectric constant $\left(\varepsilon_{\text {reff }}\right)$ :

$$
\varepsilon_{\text {reff }}=\frac{s r+1}{2}+\frac{s r-1}{\sqrt[z]{\left(1+\frac{12 h}{W}\right)}}
$$

where, $\varepsilon_{\text {reff }}$ is the Effective dielectric constant,$\varepsilon_{\mathrm{r}}$ is the dielectric constant of substrate $\mathrm{h}$ is the Height of dielectric substrate and $\mathrm{W}$ is the Width of the patch.

Effective length (Leff):

$$
\text { Leff }=\frac{c}{2 * f r \sqrt{\text { sreff }}}
$$

Calculation of patch length $(\Delta \mathrm{L})$ :

$$
\frac{\Delta L}{h}=0.412\left(\frac{(\text { sreff } f 0.3)\left(\frac{w}{h}+0.264\right)}{(\text { sreff }-0.258)\left(\frac{W}{h}+0.8\right)}\right.
$$

Length of substrate (Ls): 
$\mathrm{Ls}=\mathrm{Lp}+6 \mathrm{~h}$

Width of substrate (Ws):

$\mathrm{Ws}=\mathrm{Wp}+6 \mathrm{~h}$

Distance of feed point from $\mathrm{L}_{\mathrm{P}}(\mathrm{X})$ :

$X=\frac{\text { LP }}{2 \sqrt{\text { Ereff }}}$

Distance of feed point from $\mathrm{W}_{\mathrm{P}}(\mathrm{Y})$ :

$Y=\frac{\text { wp }}{3 \sqrt{\text { sreff }}}$

Table.1: Dimensions of proposed antenna

\begin{tabular}{|c|c|}
\hline Parameters & Calculated Values \\
\hline Resonant Frequency $\left(\mathrm{f}_{\mathrm{r}}\right)$ & $2.4 \mathrm{GHz}$ \\
\hline Substrate & FR4 \\
\hline Dielectric constant $\left(\varepsilon_{\mathrm{r}}\right)$ & 4.4 \\
\hline Substrate Height $(\mathrm{h})$ & $1.6 \mathrm{~mm}$ \\
\hline Feed & Co-axial \\
\hline Patch Width (WP $)$ & $36.10 \mathrm{~mm}$ \\
\hline Patch Length (LP ) & $27.4 \mathrm{~mm}$ \\
\hline Substrate Length (Lsub) & $38.60 \mathrm{~mm}$ \\
\hline Substrate Width (Wsub) & $46.70 \mathrm{~mm}$ \\
\hline Length of Ground Plane (Lsub $=\mathrm{Lg})$ & $38.60 \mathrm{~mm}$ \\
\hline Width of Ground Plane (Wsub $=\mathrm{Wg})$ & $46.70 \mathrm{~mm}$ \\
\hline
\end{tabular}

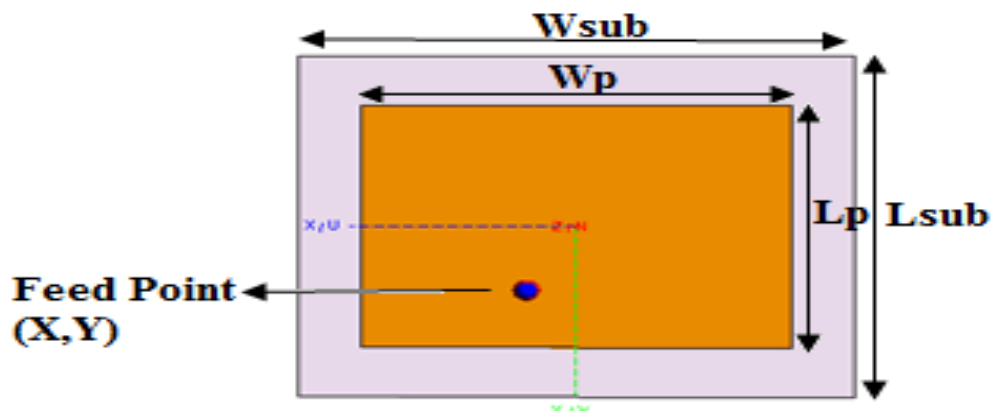

Fig.4.Coaxial feed MSA Design

The geometry of the designed microstripline feed microstrip patch antenna is as shown in fig.5. The designed antenna is realized using microstrip line feed on a $1.6 \mathrm{~mm}$ thick FR-4 dielectric substrate with dimensions of $46.70 \times 38.60 \times 1.6 \mathrm{~mm}^{3}$ and feed by aMicrostrip line feed of $50 \Omega$. The antenna is designed with full ground having dimensions same as FR-4 substrate. The relative permittivity and loss tangent of the substrate is 4.4 and 0.02 respectively. Equations (1-8) are used for the proposal of rectangular microstrip patch antenna.The feed length is $9 \mathrm{~mm}$ ad width is $1 \mathrm{mmas}$ shown in fig.5.

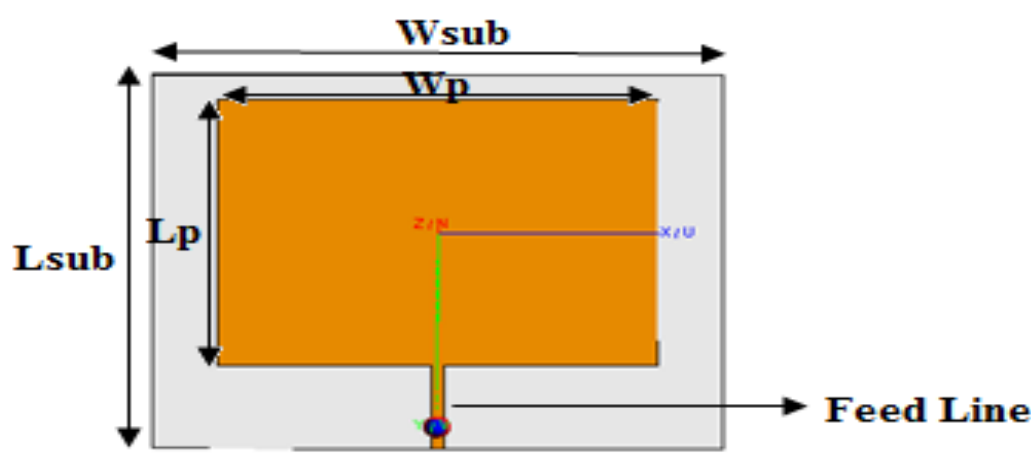

Fig.5. Microstrip feed MSA Design 


\section{SIMULATION RESULTS AND ANALYSIS}

Based on the optimized parameters of the proposed rectangular antenna with coaxial feed and micro strip line feed we obtained the Bluetooth band ( $\mathrm{fc}=2.44 \mathrm{GHz}$ ). The proposed rectangular micro strip antenna is designed, specific location of feed position for micro strip line and coaxial feeding is optimized and the various parameter of antenna are simulated using CADFEKO suite 7.0. Fig.6. shows the reflection coefficient $\leq-10 \mathrm{~dB}$. for coaxial feed MSA. It shows that for Bluetooth band we have got up to $-26.8 \mathrm{~dB}$. Fig.7.shows the reflection coefficient $\leq-10 \mathrm{~dB}$ for micro strip line feed MSA. It shows that for Bluetooth band we have got up to -16.5 $\mathrm{dB}$.from that we can say that we have got the return loss is more negative for coaxial feeding than for strip line feeding.

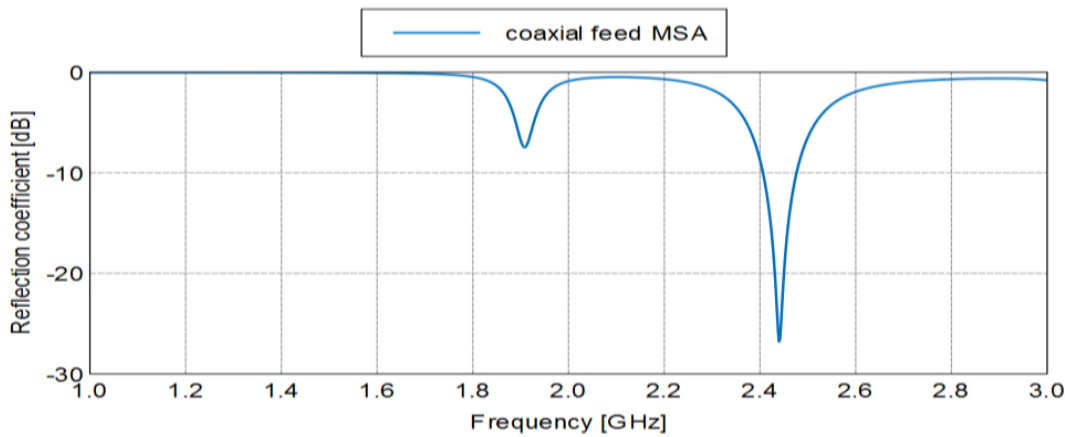

Fig .6. Reflection Coefficient versus frequency graph for coaxial feed MSA.

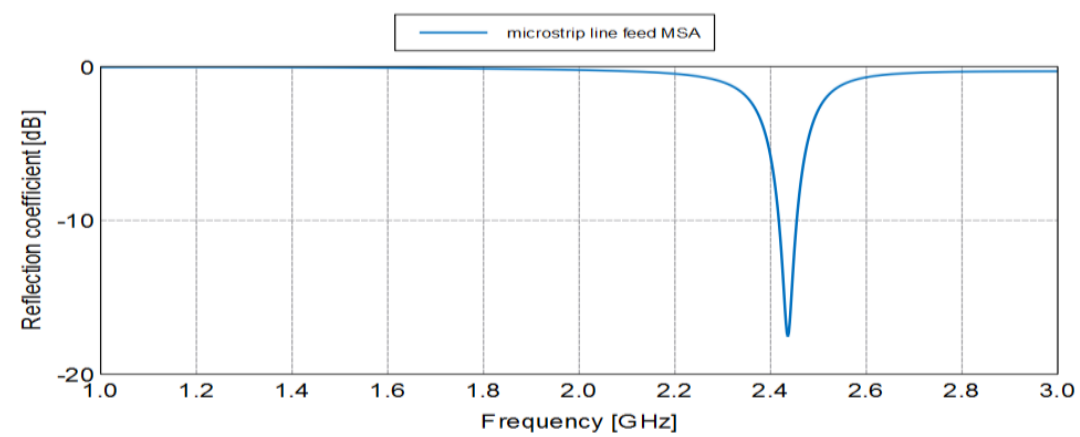

Fig.7. Reflection Coefficient versus frequency graph for Micro strip feed MSA.

Fig.8. shows the variation of VSWR with frequency. The VSWR is 1.32 for strip line feeding and 1.14 coaxial feeding at resonance frequency. Fig.9. and fig.10. shows the efficiency vs. frequency graph. Efficiency for microstrip sline feed MSA is $40.5 \%$ and for coaxial feed MSA it is $46.6 \%$.we can say that for coaxial feed MSA efficiency is more than microstrip line feed MSA. Fig.11. shows the Gain vs. frequency graph.from fig. 11. we can say that gain is more for microstrip line feed comaped to coaxial feeding.Gain for microstrip line feed is 6.023dBi and for coaxial feeding msa $2.239 \mathrm{dBi}$ shown in table.2.

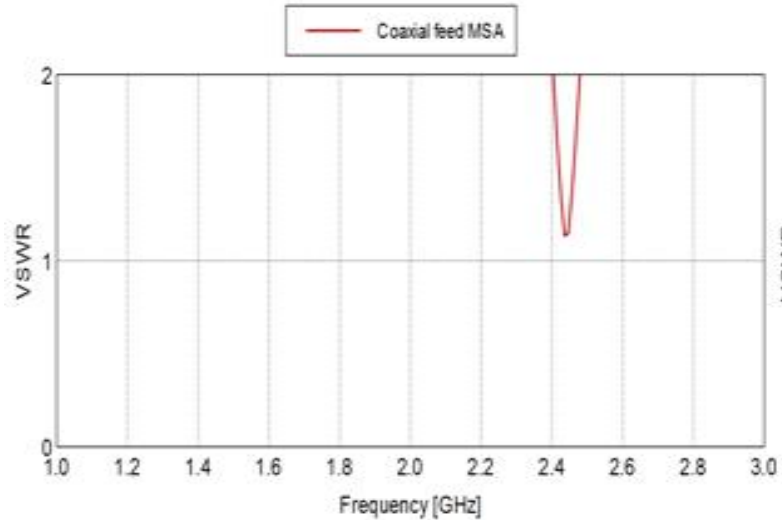

(a)

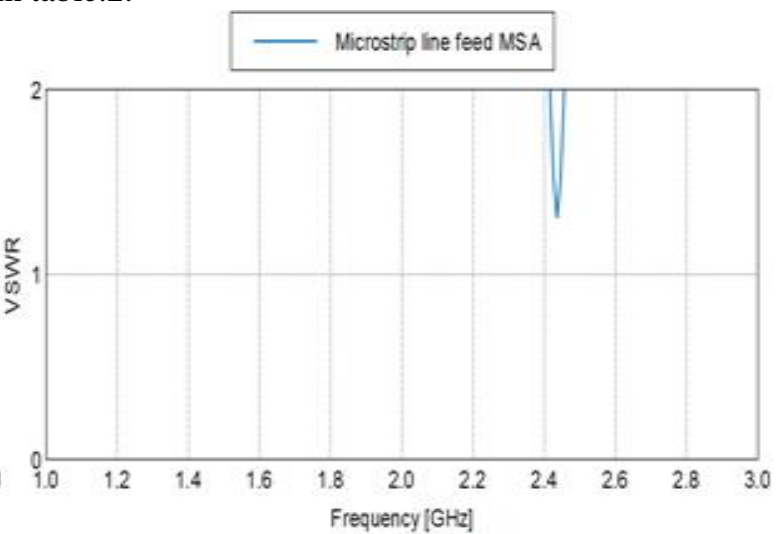

(b)

Fig.8. VSWR versus frequency graph (a)Coaxial feed MSA(b) Micro strip feed MSA 


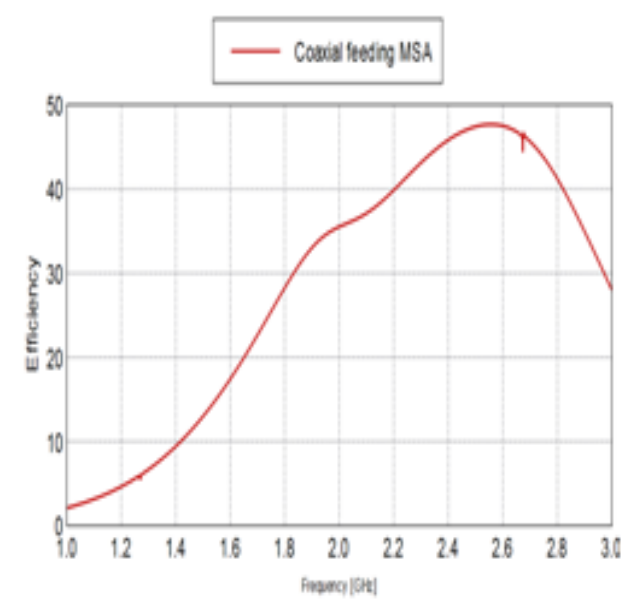

Fig.9. Efficiency vs frequency for microstrip feed

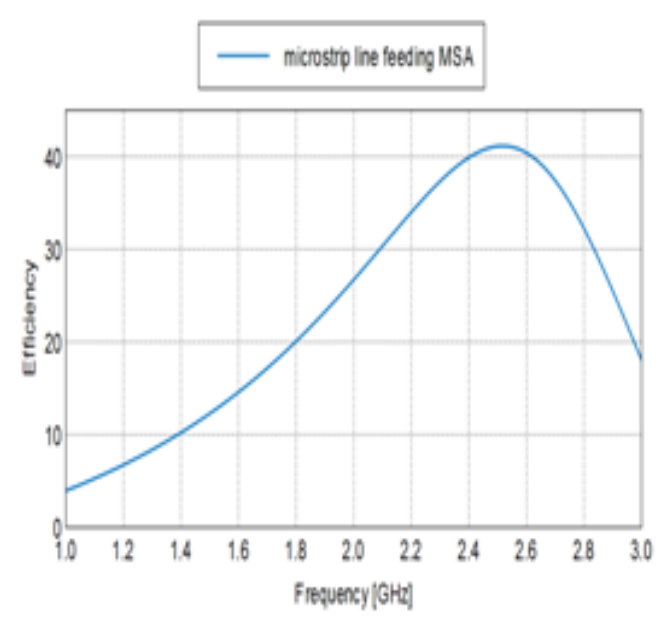

Fig.10.Efficiency vs frequency for Coaxial feed

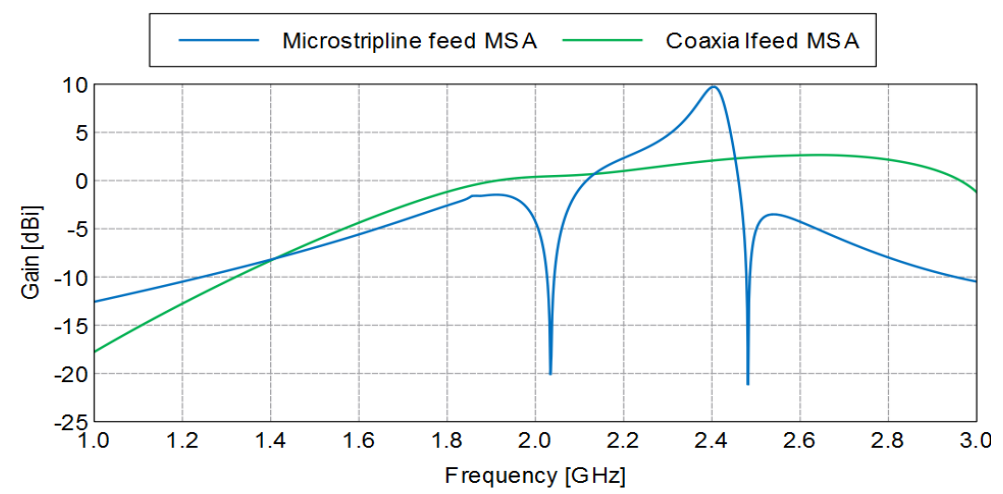

Fig.11. Gain vs frequency for coax \& microstrip feed

Fig.12.shows the radiation pattern for elevation plane (E-plane or _ $=90)$ and azimuth plane $\left(\mathrm{H}_{\text {-plane or }}\right.$ _=0) at $\mathrm{f}=2.44 \mathrm{GHz}$ for microstrip line feed msa and $\mathrm{f}=2.44 \mathrm{GHz}$ for coaxial feed msa. It describes how an antenna directs the energy it radiates [19]. It shows an Omni-directional radiation pattern along the H-plane and a directional radiation pattern along the E-plane, with low cross polarization.fig.12. (a) and (b) shows E plane radiation pattern coaxial feed msa \& microstrip line feed msa respectively. Similarly Fig.12.(c) and (d) shows H plane radiation pattern for coaxial feed msa \& microstrip line feed respectively. From that we can say that for microstrip line feed msa cross polarization is less or more negative compare to coaxial feed msa i.e. for E plane it is near to $-40 \mathrm{~dB}$ and $-30 \mathrm{~dB}$.,for E plne it is $-50 \mathrm{~dB}$ and $-27 \mathrm{~dB}$ respectively.
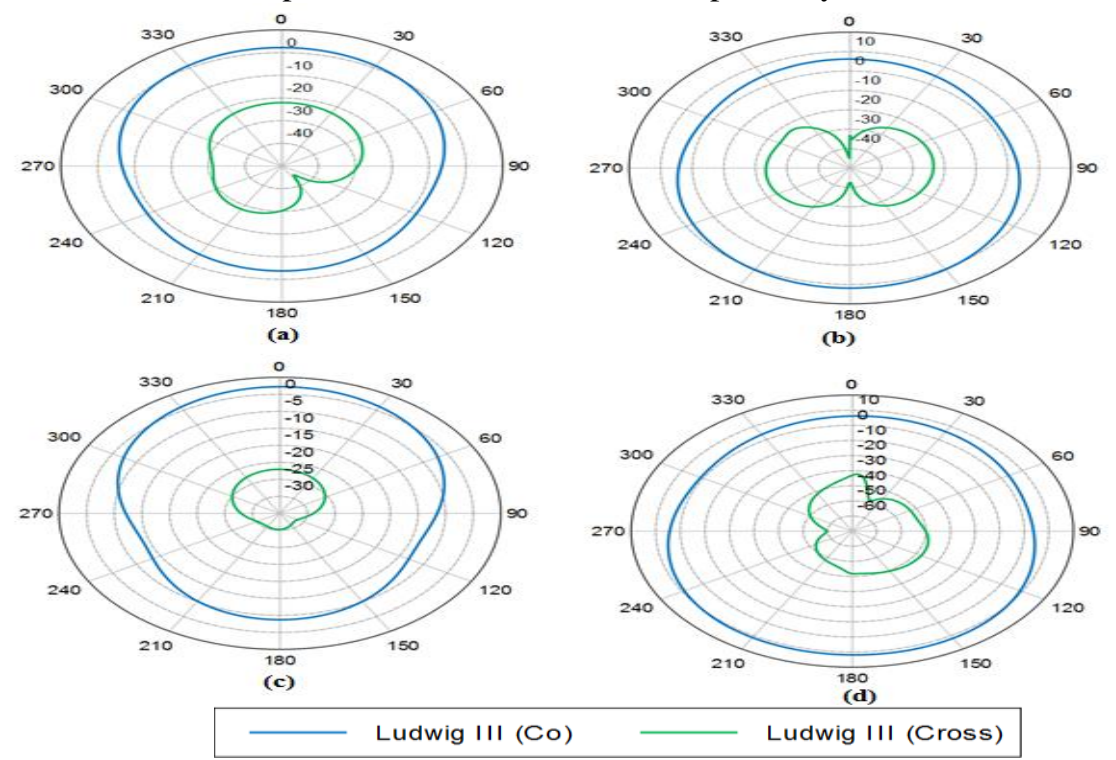
Fig.12.Simulated radiation patterns observed in E-plane at (a) $2.44 \mathrm{GHz}$ for coax feed (b) $2.437 \mathrm{GHz}$ for microstrip feed and H-plane (c) $2.44 \mathrm{GHz}$ coaxial feed and (d) $2.437 \mathrm{GHz}$ micro strip feed.

Table. 2: A Comparative Review of the results of CFT and MFT

\begin{tabular}{|c|c|c|c|}
\hline Sr No. & Antenna Parameters & Coaxial feed & Micro strip line feed \\
\hline 1. & Resonant frequency $(\mathrm{GHz})$ & 2.44 & 2.437 \\
\hline 2. & Return Loss $(\mathrm{dB})$ & -26.8 & -16.5 \\
\hline 3. & Gain $(\mathrm{dBi})$ & 2.239 & 6.022 \\
\hline 4. & Efficiency $(\%)$ & 46.6 & 40.5 \\
\hline 5. & Bandwidth $(\%)$ & 3.2 & 1.8 \\
\hline 6. & $\operatorname{VSWR}$ & 1.14 & 1.32 \\
\hline 7. & Impedance $(\Omega)$ & 54 & 37.3 \\
\hline
\end{tabular}

\section{CONCLUSION}

From this work, the strip line and coaxial fed rectangular micro strip patch antenna at $2.4 \mathrm{GHz}$ designed on FR4 substrate is studied by using CADFEKO SUITE 7.0. Their output parameters are comparatively studied, analyzed and presented in this WORK. The study conclude that, the coaxial feeding technique has more advantageous for antenna parameters, such as return loss, bandwidth,effeciency and input impedance in specified frequency range as compared to the micro strip line feeding technique. Overall the coaxial feeding is giving better results for all antenna parameters compared to micro strip line feeding excluding gain. Such antenna finds applications in WLAN and WI-FI connectivity.

\section{REFERENCES}

[1] C. Balanis, Antenna Theory, Analysis and Design, second edition (NewYork, John Wiley and Sons, 1997).

[2] K.P.Ray and Girish Kumar,Broadband Microstrip Antenna (Artech House, Boston London).

[3] A.B. Mutiara, R.Refianti, Rachmansyah, Design Of Microstrip Antenna For Wireless Communication At 2.4 GHz, Journal of Theoretical and Applied Information Technology,33(2), 2011,184-192.

[4] Ogunlade Michael Adegoke, Charles Okand aNyatega,,Design Of Dual Band Coax Patch Antenna For GSM and Bluetooth Application, International journal of science and research,3(12),998-1002,2012.

[5] Sanjay R. Bhongale, Pramod N. Vasambeka,Comparison of Stripline and Coaxial Feeding In Rectangular Microstrip Patch Antenna, International Journal of Electronics Communication and Computer Technology,5,21-24,2015.

[6] G M Pushpanjali, A B Pratima, D Ashwini, V H Vidyashree,Review paper on comparative analysis of microstripline and coaxial feeding techniques for different microstrip patch antennas, International Journal of Research in Engineering and Technology, 03(3),983-986, 2014.

[7] Amit Kumar, Jaspreet Kaur, Rajinder Singh,Performance Analysis of Different Feeding Techniques, International Journal of Emerging Technology and Advanced Engineering,3(3), 885-890,2013.

[8] Anchal Verma,O.P.Singh,Ganga Ram Mishra, Analysis of Feeding Mechanism In Microsrtip Patch Antenna, International Journal of Research in Engineering and Technology, 3(4),786-792, 2014.

[9] Rahul Verma,Nitin Vyas,Rahul Rana, Vipin Kaushik, A. K. Arya,Design Study of Microstrip Antenna with Various Feeding Techniques: A Review, International Journal of Engineering Research \& Technology, 3 , 619-622, 2014.

[10] Sourabh Bisht, Shweta Saini, Dr Ved Prakash, Bhaskar Nautiyal, Study The Various Feeding Techniques of Microstrip Antenna Using Design and Simulation Using CST Microwave Studio, International Journal of Emerging Technology and Advanced Engineering, 4(9), 318-324, 2014. 